\title{
Inheritance of Resistance to Gray Leaf Spot in Crosses Involving Selected Resistant Inbred Lines of Corn
}

\author{
S. T. Coates and D. G. White
}

Department of Crop Sciences, University of Illinois, Urbana 61801.

Accepted for publication 31 May 1998.

\begin{abstract}
Coates, S. T., and White, D. G. 1998. Inheritance of resistance to gray leaf spot in crosses involving selected resistant inbred lines of corn. Phytopathology 88:972-982.

Three populations derived from crosses of selected resistant inbreds (061, B37HtN , and DS:74:1071) with susceptible inbred FR1141 and a population derived from a cross of $\mathrm{B} 37 \times \mathrm{B} 37 \mathrm{HtN}$ were evaluated for gray leaf spot severity in 1992 and 1993 at Urbana, IL, and Andrews, NC. Populations included the susceptible parent $\left(\mathrm{P}_{1}\right)$, the resistant parent $\left(\mathrm{P}_{2}\right), \mathrm{F}_{1}$ and $\mathrm{F}_{2}$ generations, backcrosses $\mathrm{BCP}_{1}$ and $\mathrm{BCP}_{2}$, and, when space and seed were available, one or more of the $\mathrm{F}_{3}, \mathrm{BCP}_{1} \mathrm{~S}_{1}$, and $\mathrm{BCP}_{2} \mathrm{~S}_{1}$ generations.
\end{abstract}

ABSTRACT
Plants at Urbana were inoculated, and naturally occurring disease was relied upon at Andrews. Individual plants were rated by visually estimating the percent leaf area blighted (necrotic). Generation mean analysis of data combined over years or locations indicated that a simple additive-dominance model was able to explain the inheritance of resistance for all populations. Dominance effects were detected in all population evaluated. For the FR1141 $\times 061$ and FR1141 $\times$ B 37HtN populations, dominance was significant at early ratings, but not at late ratings. Results from generation mean analysis for individual years, locations, and rating were variable.

Additional keywords: Cercospora zeae-maydis, maize.
Gray leaf spot, a foliar disease of corn (Zea mays L.) caused by Cercospora zeae-maydis Tehon and E.Y. Daniels was first described in 1925 from lesions found on corn in Alexander County, Illinois (42). The disease occurred in the 1940s to 1960s in Kentucky (24), North Carolina (27), South Carolina (2,25), Tennessee (24), and Virginia (35). These few incidences of disease did not cause alarm. In the 1970s, an increase in the incidence and severity of gray leaf spot in the eastern United States, particularly in mountainous regions $(21,26,28,36)$, was associated with the use of conservation tillage systems $(26,36)$. By leaving colonized plant debris on the soil surface, the use of conservation tillage results in larger amounts of overwintered fungal tissue as compared with conventional tillage. This can lead to the production of large amounts of inoculum by C. zeae-maydis $(12,33)$, which can result in severe gray leaf spot epidemics $(13,32)$. Gray leaf spot is now recognized as a serious problem in the eastern and midwestern United States, primarily in areas where conservation tillage is widely used.

Potential methods of gray leaf spot control are to discontinue conservation tillage, use crop rotation, apply foliar fungicides, and grow hybrids with resistance. Since wind can disseminate inoculum of C. zeae-maydis from field to field (26), the effectiveness of crop rotation and conventional tillage for gray leaf spot control may depend on the number of growers in a region that utilize these controls. Also, it is important to preserve the economic and environmental advantages of conservation tillage systems. For these reasons, tillage is not a viable control option and crop rotation may not be an effective control. Foliar applied fungicides are effective means of control, but may not be economical for grain production. Therefore, host resistance is expected to be the most effective, efficient, and acceptable method to control gray leaf spot, and improving U.S. corn belt germ plasm for resistance to gray leaf spot has become an important objective of many corn breeding programs in the Midwest.

Corresponding author: D. G. White; E-mail address: d-white@uiuc.edu

Publication no. P-1998-0702-02R

(C) 1998 The American Phytopathological Society
Corn germ plasm has been evaluated for resistance to gray leaf spot under conditions of natural infection $(6,14,15,17,18,21,22,36$, $38,39,43,46)$ and with laboratory-produced inoculum $(9-11,16,22)$. Some of these evaluations included studies of the inheritance of resistance using diallel analysis $(14,15,17,22,43,46)$, generation mean analysis $(9,43)$, and statistical modeling of resistance $(15)$, and by examination of quantitative trait loci (QTL) and restriction fragment length polymorphisms (RFLPs) associated with resistance $(6,39)$. Diallel analyses have found general combining ability $(14,15,17,22$, $43,46)$ and specific combining ability $(14,15,17,22)$ to be significant for the inbreds studied. Generation mean analyses have indicated that resistance is inherited additively within the populations studied $(9,43)$. Statistical modeling of resistance has indicated that dominance effects for resistance to gray leaf spot exists (15). Bubeck et al. (6) studied QTL associated with resistance in three populations and found that the QTL associated with resistance differed between environments. Some marker-associated effects showed dominance, but most indicated additive gene action. Saghai-Maroof et al. (39) studied QTL from a cross of Va14 and B73 and found QTL that were associated with additive, dominance, recessive, and epistatic effects. The QTL associated with dominance effects came from B73.

Although sources of resistance have been identified, more sources would be useful, particularly those that can contribute resistance to B73-type inbred lines that are susceptible to gray leaf spot and are widely used as parents in commercial hybrids in the midwestern United States. The objectives of gray leaf spot research at the University of Illinois were to identify new sources of resistance and determine the inheritance of that resistance. In the summer of 1989, 1,396 inbred corn lines were evaluated for resistance to gray leaf spot (11). The lines evaluated were a mixture of domestic, foreign, and University of Illinois inbreds. From these lines, 62 inbreds were selected for further study based on disease reactions, lesion types, and maturities useful for breeding in central Illinois. In 1990, inbreds selected in 1989 and their $\mathrm{F}_{1}$ crosses with FR1141, a B73type inbred line, were evaluated (11). From the results of the 1989 and 1990 experiments, 24 inbreds were selected for further evaluation based on reactions of the inbreds and the $F_{1}$ crosses with FR1141. Populations that included segregating generations were produced 
from crosses of these inbreds with susceptible inbreds and evaluated for gray leaf spot in 1991 (10).

Three of the most resistant inbreds found in these studies, 061, B37HtN, and DS:74:1071, are unreleased inbreds developed at the University of Illinois by A. L. Hooker. The inbred 061 was derived from PI 320061. B37HtN was derived from PI 406119, which is INB.A553N from South Africa. The source of the HtN gene was Pepitilla (NSL 2843) (20). Pepitilla was backcrossed twice to B37 to produce INB.A553N $(1,20)$, which has yellow kernels (1). However, our seed has a white endosperm with a bronze color in the pericarp. INB.A553N is reported to be variable (20), and this may be why the kernels have this appearance. Although this inbred is not nearly isogenic with $\mathrm{B} 37$, and $\mathrm{B} 37 \mathrm{HtN}$ may not be the best designation, it has been used for this line in other experiments and will be retained here. The breeding records for DS:74:1071 are incomplete, but it appears to be derived from a synthetic population originally designed to produce inbreds with Texas male-sterile cytoplasm (Cms-T) and resistance to southern corn leaf blight races $\mathrm{O}$ and $\mathrm{T}$ caused by Cochliobolus heterostrophus (Drechs.) Drechs. (anamorph: Bipolaris maydis (Nisikado \& Miyake) Shoemaker $=$ Helminthosporium maydis Nisikado \& Miyake).

The objective of this research was to determine the inheritance of resistance to gray leaf spot from these three sources. Understanding the inheritance of resistance in these lines in crosses with a B73-type inbred would aid in their use in breeding programs in which resistance to gray leaf spot is important. Generation mean analysis was chosen to study the inheritance of resistance, because it provides more information than diallel analysis and because populations used for generation mean analysis provide generations that can be used in a breeding program. Generation mean analysis has been used in previous studies of the inheritance of resistance to gray leaf spot $(9,43)$ and other diseases of corn $(7,8,23,30,45)$.

\section{MATERIALS AND METHODS}

Generations evaluated. The three gray leaf spot-resistant inbred corn lines 061, B37HtN, and DS:74:1071 were crossed with FR1141 and segregating generations produced. In addition, a population was produced from a cross of B37HtN with the related line B37. All populations evaluated included the susceptible parent $\left(\mathrm{P}_{1}\right)$, the resistant parent $\left(\mathrm{P}_{2}\right)$, the $\mathrm{F}_{1}$ cross between the two parents, the $\mathrm{F}_{2}$ generation, the backcross to the susceptible parent $\left(\mathrm{BCP}_{1}\right)$, and the backcross to the resistant parent $\left(\mathrm{BCP}_{2}\right)$. One or more of the $\mathrm{F}_{3}$, the backcross to the susceptible parent selfed once $\left(\mathrm{BCP}_{1} \mathrm{~S}_{1}\right)$, and the backcross to the resistant parent selfed once $\left(\mathrm{BCP}_{2} \mathrm{~S}_{1}\right)$ generations were included where adequate space was available (Table 1).

Field plots. Populations were evaluated in 1992 and 1993 at Urbana, IL, at the Agronomy-Plant Pathology South Farm, and at Andrews, NC, in plots provided by Pioneer Hi-Bred International, Inc. The experimental design was a split plot of a randomized complete block design. Fields at each location were divided into two blocks (replications). Populations (main plots) were randomized within each block, and generations (subplots) were randomized within their respective populations. Families of $\mathrm{F}_{3}, \mathrm{BCP}_{1} \mathrm{~S}_{1}$, and $\mathrm{BCP}_{2} \mathrm{~S}_{1}$ generations were randomized within their respective generations. Plants were rated twice, and the ratings were treated as a split plot in time (41) except at Urbana in 1992, where plants were rated once.

For each population, 2 rows of each of the $\mathrm{P}_{1}, \mathrm{P}_{2}$, and $\mathrm{F}_{1}$ generations, 10 rows of the $F_{2}$ generation, and 5 rows of each of the $\mathrm{BCP}_{1}$ and $\mathrm{BCP}_{2}$ generations were evaluated per replicate. In 1992, two rows of each family of the $\mathrm{F}_{3}$ and $\mathrm{BCP}_{1} \mathrm{~S}_{1}$ generations and one row of each family of the $\mathrm{BCP}_{2} \mathrm{~S}_{1}$ generation were evaluated per replicate. In 1993, one row of each family of the $\mathrm{F}_{3}, \mathrm{BCP}_{1} \mathrm{~S}_{1}$, and $\mathrm{BCP}_{2} \mathrm{~S}_{1}$ generations was evaluated per replicate. At Urbana, plots were hand-planted on 5 to 7 May in 1992 and on 10 to 11 May in 1993 into 4.2-m rows spaced $76.2 \mathrm{~cm}$ apart with 24 kernels per row. At Andrews, plots were planted on 1 May 1992 and 10
May 1993 into 4.2-m rows spaced $76.2 \mathrm{~cm}$ apart with 30 kernels per row for inbreds and 24 kernels per row for the other generations. The field at Andrews was not tilled, and seed was machine-planted into corn residues from the previous season. Plots at Urbana were thinned to 12 plants per row approximately 5 weeks after planting. Plots at Andrews were not thinned.

Inoculations. Plants at Andrews were not inoculated, because this location has severe gray leaf spot epidemics every year. Plants were inoculated at Urbana, where gray leaf spot tends to occur late in the growing season. Also, due to the high humidity requirements for gray leaf spot development $(4,5,37,44)$, plants at Urbana were irrigated as needed with a low-output overhead-mist irrigation system as in previous experiments (11).

Differences in aggressiveness between isolates of $C$. zeae-maydis have been detected (3); therefore, plants at Urbana were inoculated with a propagule suspension containing a mixture of isolates. In 1992, 8 isolates of C. zeae-maydis were used, and 12 isolates were used in 1993. Most of the isolates were obtained from samples submitted to the University of Illinois plant clinic and from various University of Illinois research personnel. Stock cultures of $C$. zeae-maydis were maintained on clarified V8 agar ( $300 \mathrm{ml}$ of clarified V8 vegetable juice, $20 \mathrm{~g}$ of agar, and $700 \mathrm{ml}$ of deionized water per liter) in $100-\mathrm{mm}$ petri dishes. Growing the fungus on clarified V8 facilitates the detection of contaminants. To clarify the V8 juice, $\mathrm{CaCO}_{3}$ was added to $\mathrm{V} 8$ juice at a rate of $8.82 \mathrm{~g} / \mathrm{liter}$, and the mixture was shaken to suspend the $\mathrm{CaCO}_{3}$. This mixture was autoclaved at $121^{\circ} \mathrm{C}$ for $20 \mathrm{~min}$. Autoclaving accelerates neutralization of the acids in the $\mathrm{V} 8$ juice by the $\mathrm{CaCO}_{3}$ and makes the pulp in the juice easier to remove. After cooling, the mixture was clarified by vacuum-filtration through a layer of shredded paper towels and a layer of diatomaceous earth over a filter paper disk in a 17.2-cm Büchner funnel. The clarified V8 juice was kept frozen until needed. Stock cultures were transferred by inverting a piece of agar with sporulating fungus onto fresh agar and streaking it across the agar (22). The stock cultures were incubated at approximately $25^{\circ} \mathrm{C}$ with approximately $12 \mathrm{~h}$ of light per day.

Stock cultures of $C$. zeae-maydis were mixed together to produce inoculum by blending in sterile deionized water. The blend $(2 \mathrm{ml})$ was spread onto fresh clarified V8 agar amended with $0.25 \mathrm{~g}$ of streptomycin sulfate per liter to control bacterial contaminants. Cultures were grown at room temperature for 7 to 10 days with approximately $12 \mathrm{~h}$ of light per day. Inoculum was prepared by blending cultures in deionized water. The suspension was diluted with water and Tween 20 surfactant added at a rate of $0.2 \mathrm{ml} / \mathrm{liter}$. The resulting suspension was sprayed onto plants with backpack sprayers (Solo model 425; Solo Inc., Newport News, VA) using cone nozzles.

In 1992, plants were inoculated six times between mid-June and mid-July. At each inoculation, inoculum was sprayed into the whorls of the plants and also onto the undersides of the leaves from both sides of a row. For the whorl inoculations, approximately 14 petri-

TABLE 1. The number of families evaluated from the $\mathrm{F}_{3}, \mathrm{BCP}_{1} \mathrm{~S}_{1}$, and $\mathrm{BCP}_{2} \mathrm{~S}_{1}$ generations from four populations evaluated for severity ${ }^{\mathrm{a}}(\%)$ of gray leaf spot at Urbana, IL, and Andrews, NC, in 1992 and 1993

\begin{tabular}{|c|c|c|c|c|c|}
\hline \multirow[b]{2}{*}{ Population } & \multirow[b]{2}{*}{ Location } & \multirow[b]{2}{*}{ Year } & \multicolumn{3}{|c|}{ Number of families } \\
\hline & & & $\mathrm{F}_{3}$ & $\mathrm{BCP}_{1} \mathrm{~S}_{1}$ & $\mathrm{BCP}_{2} \mathrm{~S}_{1}$ \\
\hline \multirow[t]{3}{*}{ FR1141 ×061 } & Urbana & 1992 & 50 & 30 & 30 \\
\hline & Urbana & 1993 & 96 & 34 & 40 \\
\hline & Andrews & 1993 & 100 & 40 & $\ldots{ }^{b}$ \\
\hline \multirow[t]{2}{*}{$\mathrm{B} 37 \times \mathrm{B} 37 \mathrm{HtN}$} & Urbana & 1993 & 76 & 40 & 40 \\
\hline & Andrews & 1993 & 58 & $\ldots$ & $\ldots$ \\
\hline \multirow[t]{2}{*}{$\mathrm{FR} 1141 \times \mathrm{B} 37 \mathrm{HtN}$} & Urbana & 1992 & 36 & 33 & 30 \\
\hline & Urbana & 1993 & 76 & 40 & 40 \\
\hline \multirow[t]{2}{*}{ FR1141 × DS:74:1071 } & Urbana & 1992 & 50 & 30 & 30 \\
\hline & Urbana & 1993 & 76 & 40 & 40 \\
\hline
\end{tabular}

a Visual estimate of the percent leaf area blighted (necrotic).

${ }^{\mathrm{b}}$ Generation not evaluated. 
dish cultures of $C$. zeae-maydis from 100-mm petri dishes were used to make approximately 12.8 liters of inoculum per 1,000 plants with an approximate concentration of $5.8 \times 10^{3}$ conidia per $\mathrm{ml}$ as measured with a hemacytometer. For the inoculation of the undersides of the leaves, approximately 14 petri-dish cultures of $C$. zeae-maydis were used to make approximately 25.1 liters of inoculum per 1,000 plants with an approximate concentration of $2.9 \times 10^{3}$ conidia per ml.

In 1993, plants were inoculated five times between mid-June and mid-July. Plants were inoculated by spraying a propagule suspension onto the undersides of the leaves from both sides of a row. Approximately 24 petri-dish cultures of C. zeae-maydis were used to make approximately 25.2 liters of inoculum per 1,000 plants with an approximate concentration of $6.2 \times 10^{3}$ conidia per $\mathrm{ml}$.

Disease ratings. Disease severity was rated by visually estimating the percent leaf area blighted (necrotic) on individual plants. Chlorotic lesions can be an indication of resistance to gray leaf spot (16). Therefore, we chose to estimate the percent necrotic tissue only. At Urbana, plants were rated once between 26 August and 28 September 1992. Populations were rated one at a time so that ratings were made within populations in as short a period of time as possible. At Andrews, plants were rated twice, from 18 to 20 August and from 14 to 15 September 1992. In 1993, plants were rated twice from 2 to 14 August and 7 September to 1 October at Urbana, and from 23 to 25 August and 13 to 14 September at Andrews.

Data analysis. Means of generations within each replication were calculated from individual plant ratings in the $\mathrm{P}_{1}, \mathrm{P}_{2}, \mathrm{~F}_{1}, \mathrm{~F}_{2}$, $\mathrm{BCP}_{1}$, and $\mathrm{BCP}_{2}$ generations (Table 2). For the $\mathrm{F}_{3}, \mathrm{BCP}_{1} \mathrm{~S}_{1}$, and $\mathrm{BCP}_{2} \mathrm{~S}_{1}$ generations, means of families within each replication were calculated from individual plant ratings within each family, and generation means within each replication were calculated from the family means. Families with fewer than five plants in a repli- cation were not used in calculations of generation means. Generation mean analysis (29) was done by multiple regression using unweighted means. Data from individual years, locations, and ratings for each population were analyzed separately, beginning with a simple model that included pooled additive effects and pooled dominance effects, described in the formula $Y=m+a x+b_{1} d+$ $b^{2} h$, in which $Y=$ generation mean, $m=$ midparent and intercept value, $x=$ block effect, $d=$ pooled additive genetic effects (pooled effects of homozygous loci), and $h=$ pooled dominance effects (pooled effects of heterozygous loci). The adequacy of the model was tested by partitioning the type I (sequential) sums of squares accounted for by generations into the sums of squares accounted for by the genetic effects and deviations from the model. An $F$ test was used to determine if deviations from the model were significant. If deviations from the model were not significant, then the additive-dominance model was considered adequate. If deviations were significant, then a model that included the digenic interaction parameters was tested. The equation used in this regression analysis was $Y=m+a x+b_{1} d+b_{2} h+b_{3} i+b_{4} j+b_{5} l$, in which $Y=$ generation mean, $m=$ mean of the $\mathrm{F}_{\infty}$ generation and intercept value, $x=$ block effect, $d=$ pooled additive genetic effects, $h=$ pooled dominance effects, $i=$ additive $\times$ additive (homozygote $\times$ homozygote) interactions, $j=$ additive $\times$ dominance (homozygote $\times$ heterozygote) interactions, and $l=$ dominance $\times$ dominance (heterozygote $\times$ heterozygote) interactions.

In addition, generation means from Andrews, NC, for 1992 and 1993 were combined and analyzed using only generations evaluated in both years (Table 2) in order to maintain balanced data. The use of type I sums of squares requires balanced data. The regression equation used for this analysis was $Y=m+c y+a_{1} x_{(1992)}+$ $a_{2} x_{(1993)}+b_{1} d+b_{2} h$, in which $Y=$ generation mean, $m=$ mid-

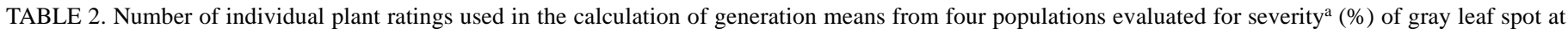
Urbana, IL, and Andrews, NC, in 1992 and 1993

\begin{tabular}{|c|c|c|c|c|c|c|c|c|c|c|c|}
\hline \multirow[b]{2}{*}{ Population, location } & \multirow[b]{2}{*}{ Year } & \multirow[b]{2}{*}{ Rating time } & \multicolumn{9}{|c|}{ Number of individual plant ratings ${ }^{b}$} \\
\hline & & & $\mathrm{P}_{1}$ & $\mathrm{BCP}_{1}$ & $\mathrm{BCP}_{1} \mathrm{~S}_{1}$ & $\mathrm{~F}_{1}$ & $\mathrm{~F}_{2}$ & $\mathrm{~F}_{3}$ & $\mathrm{BCP}_{2}$ & $\mathrm{BCP}_{2} \mathrm{~S}_{1}$ & $\mathrm{P}_{2}$ \\
\hline \multicolumn{12}{|l|}{ FR1141 × 061} \\
\hline Urbana & 1992 & Aug.-Sept. & 27 & 70 & 1,030 & 33 & 189 & 1,737 & 92 & 556 & 40 \\
\hline Urbana & 1993 & August & 35 & 99 & 557 & 38 & 196 & 1,729 & 98 & 770 & 39 \\
\hline Urbana & 1993 & September & 30 & 98 & 494 & 39 & 192 & 1,542 & 94 & 720 & 40 \\
\hline Andrews & 1992 & August & 67 & 184 & $\ldots{ }^{c}$ & 76 & 412 & $\ldots$ & 202 & $\ldots$ & 84 \\
\hline Andrews & 1992 & September & 66 & 168 & $\ldots$ & 77 & 376 & $\ldots$ & 207 & $\ldots$ & 83 \\
\hline Andrews & 1993 & August & 64 & 151 & 1,154 & 59 & 294 & 2,815 & 145 & $\ldots$ & 89 \\
\hline Andrews & 1993 & September & 66 & 130 & 1,133 & 58 & 277 & 2,728 & 134 & $\ldots$ & 88 \\
\hline \multicolumn{12}{|l|}{$\mathrm{B} 37 \times \mathrm{B} 37 \mathrm{HtN}$} \\
\hline Urbana & 1992 & Aug.-Sept. & 29 & 88 & $\ldots$ & 38 & 184 & $\ldots$ & 95 & $\ldots$ & 27 \\
\hline Urbana & 1993 & August & 38 & 92 & 764 & 38 & 193 & 1,438 & 92 & 749 & 36 \\
\hline Urbana & 1993 & September & 32 & 84 & 672 & 40 & 182 & 1,296 & 85 & 738 & 34 \\
\hline Andrews & 1992 & August & 78 & 212 & $\ldots$ & 61 & 422 & $\ldots$ & 155 & $\ldots$ & 65 \\
\hline Andrews & 1992 & September & 78 & 188 & $\ldots$ & 60 & 411 & $\ldots$ & 154 & $\ldots$ & 62 \\
\hline Andrews & 1993 & August & 71 & 127 & $\ldots$ & 63 & 276 & 1,628 & 114 & $\ldots$ & 77 \\
\hline Andrews & 1993 & September & 73 & 114 & $\ldots$ & 63 & 255 & 1,530 & 115 & $\ldots$ & 56 \\
\hline \multicolumn{12}{|l|}{$\mathrm{FR} 1141 \times \mathrm{B} 37 \mathrm{HtN}$} \\
\hline Urbana & 1992 & Aug.-Sept. & 31 & 91 & 1,103 & 31 & 148 & 1,002 & 94 & 392 & 34 \\
\hline Urbana & 1993 & August & 36 & 99 & 722 & 39 & 195 & 1,289 & 98 & 729 & 41 \\
\hline Urbana & 1993 & September & 36 & 88 & 665 & 39 & 172 & 1,196 & 94 & 690 & 41 \\
\hline Andrews & 1992 & August & 63 & 203 & $\ldots$ & 77 & 398 & $\ldots$ & 213 & $\ldots$ & 52 \\
\hline Andrews & 1992 & September & 56 & 179 & $\ldots$ & 79 & 389 & $\ldots$ & 216 & $\ldots$ & 54 \\
\hline Andrews & 1993 & August & 73 & 167 & $\ldots$ & 61 & 309 & $\ldots$ & 133 & $\ldots$ & 65 \\
\hline Andrews & 1993 & September & 68 & 158 & $\ldots$ & 54 & 267 & $\ldots$ & 136 & $\ldots$ & 72 \\
\hline \multicolumn{12}{|l|}{ FR1141 × DS:74:1071 } \\
\hline Urbana & 1992 & Aug.-Sept. & 26 & 76 & 941 & 37 & 162 & 1,468 & 87 & 505 & 35 \\
\hline Urbana & 1993 & August & 43 & 98 & 654 & 41 & 212 & 1,304 & 113 & 714 & 39 \\
\hline Urbana & 1993 & September & 39 & 103 & 633 & 41 & 204 & 1,307 & 112 & 723 & 39 \\
\hline Andrews & 1992 & August & 59 & 138 & $\ldots$ & 78 & 237 & $\ldots$ & 177 & $\ldots$ & 90 \\
\hline Andrews & 1992 & September & 60 & 124 & $\ldots$ & 76 & 216 & $\ldots$ & 171 & $\ldots$ & 88 \\
\hline Andrews & 1993 & August & 56 & 147 & $\ldots$ & 62 & 302 & $\ldots$ & 151 & $\ldots$ & 69 \\
\hline Andrews & 1993 & September & 54 & 133 & $\ldots$ & 62 & 293 & $\ldots$ & 149 & $\ldots$ & 62 \\
\hline
\end{tabular}

a Visual estimate of the percent leaf area blighted (necrotic).

b Sum of the number of individual whole-plant ratings from two replications. $P_{1}$ is the susceptible parent and $P_{2}$ is the resistant parent.

c Generation not evaluated. 
parent and intercept value, $y=$ year effect, $x_{(1992)}=$ block effect in 1992, $x_{(1993)}=$ block effect in 1993 (blocks were nested within years), $d=$ pooled additive effects, and $h=$ pooled dominance effects. This model was tested for adequacy using the year $\times$ generation interaction as an error term. Generation mean analysis was also done on generation means from Urbana and Andrews for the data from 1993 using only generations evaluated in both locations. The equation used was $Y=m+c l+a_{1} x_{\text {(Urbana) }}+a_{2} x_{\text {(Andrews) }}+b_{1} d+$ $b_{2} h$, in which $l=$ location effect, $x_{\text {(Urbana) }}=$ block effect in Urbana), $x_{\text {(Andrews) }}=$ block effect in Andrews (blocks were nested within locations), $d=$ pooled additive effects, and $h=$ pooled dominance effects. This model was tested for adequacy using the location $\times$ generation interaction as an error term.

The values for the coefficient $a$ and $c$ were determined according to Neter et al. (31). The values for the coefficients $b_{1}$ to $b_{5}$ were from Mather and Jinks (29) and were for the associated condition in which the genes for the trait being studied are concentrated in one parent of the cross. Significant deviations from the additive-dominance model indicate the presence of epistasis (29). Deviations from the digenic interaction model indicate the presence of trigenic or higher-order interactions or linkage of interacting genes. Models containing trigenic or higher-order interaction parameters or parameters that account for the linkage of interacting genes were not tested, because the populations had insufficient numbers of generations for these tests. Parameter estimates for the models were tested for significance using a $t$ test, equivalent to a type II (partial) sums of squares $F$ test, in which the $t$ value is equal to the parameter estimate divided by its standard error.
The statistical analyses were done with Statistical Analysis System (SAS) software (SAS Institute, Cary, NC). The regression procedure (PROC REG) was used to do the regression, to calculate the type I sums of squares accounted for by the genetic effect parameters used in partitioning the sums of squares accounted for by generations, and to obtain estimates of the model parameters. The $t$ test provided by the regression procedure was used to test the parameter estimates for significance. Residuals from the regression analyses were tested for normality using the Shapiro-Wilk test (40) provided by the univariate procedure (PROC UNIVARIATE). $\mathrm{F}_{1}$-midparent differences were tested for significance using the $t$ test procedure (PROC TTEST). The general linear models procedure (PROC GLM) was used to analyze the effects of years, locations, rating times, generations, and interactions between these factors. Significance of these factors were tested using type IV sums of squares, as the data was unbalanced. Data from Andrews in 1992 and 1993 were combined to test the effects of years. Data from Andrews and Urbana in 1993 was combined to test the effects of locations. Years and blocks were considered random effects, and the other factors were considered fixed effects. August ratings were considered early ratings, and September ratings were considered late ratings. The single rating time in 1992 at Urbana could not be classified as either an early or late rating time and was not used in the analyses of variance for the effects of these factors. For generation mean analysis, the GLM procedure was used to obtain the sums of squares for generations and the error mean squares for testing model adequacy. Broad-sense heritability estimates were calculated for data from individual years, locations, and ratings

TABLE 3. Generation means from four populations evaluated for severity ${ }^{\mathrm{a}}$ (\%) of gray leaf spot at Urbana, IL, and Andrews, NC, in 1992 and 1993

\begin{tabular}{|c|c|c|c|c|c|c|c|c|c|c|c|c|c|}
\hline \multirow[b]{2}{*}{ Population, location } & \multirow[b]{2}{*}{ Year } & \multirow[b]{2}{*}{ Rating time } & \multicolumn{9}{|c|}{ Generation means ${ }^{b}$} & \multirow[b]{2}{*}{ Midparent $^{\mathrm{c}}$} & \multirow[b]{2}{*}{$\mathrm{F}_{1}$-midparent } \\
\hline & & & $\mathrm{P}_{1}$ & $\mathrm{BCP}_{1}$ & $\mathrm{BCP}_{1} \mathrm{~S}_{1}$ & $\mathrm{~F}_{1}$ & $\mathrm{~F}_{2}$ & $\mathrm{~F}_{3}$ & $\mathrm{BCP}_{2}$ & $\mathrm{BCP}_{2} \mathrm{~S}_{1}$ & $\mathrm{P}_{2}$ & & \\
\hline \multicolumn{14}{|l|}{ FR1141 × 061} \\
\hline Urbana & 1992 & Aug.-Sept. & 39 & 21 & 30 & 14 & 22 & 20 & 8 & 7 & 3 & 21 & $-8^{*}$ \\
\hline Urbana & 1993 & August & 22 & 12 & 13 & 3 & 7 & 8 & 2 & 5 & 3 & 12 & $-9 *$ \\
\hline Urbana & 1993 & September & 95 & 92 & 94 & 81 & 89 & 90 & 71 & 82 & 68 & 82 & 0 \\
\hline Andrews & 1992 & August & 62 & 30 & $\ldots^{\mathrm{e}}$ & 4 & 15 & $\ldots$ & 5 & $\ldots$ & 2 & 32 & $-28 * *$ \\
\hline Andrews & 1992 & September & 95 & 92 & $\ldots$ & 41 & 73 & $\ldots$ & 42 & $\ldots$ & 23 & 59 & -18 \\
\hline Andrews & 1993 & August & 90 & 57 & 61 & 5 & 22 & 38 & 7 & $\ldots$ & 5 & 47 & $-42 * *$ \\
\hline Andrews & 1993 & September & 95 & 95 & 95 & 54 & 90 & 92 & 72 & $\ldots$ & 52 & 74 & -20 \\
\hline \multicolumn{14}{|l|}{$\mathrm{B} 37 \times \mathrm{B} 37 \mathrm{HtN}$} \\
\hline Urbana & 1992 & Aug.-Sept. & 22 & 12 & $\ldots$ & 5 & 6 & $\ldots$ & 1 & $\ldots$ & 1 & 11 & -6 \\
\hline Urbana & 1993 & August & 20 & 8 & 14 & 5 & 8 & 9 & 4 & 5 & 3 & 12 & $-7 * *$ \\
\hline Urbana & 1993 & September & 95 & 77 & 93 & 52 & 86 & 85 & 76 & 76 & 72 & 83 & $-32 * *$ \\
\hline Andrews & 1992 & August & 48 & 32 & $\ldots$ & 4 & 12 & $\ldots$ & 2 & $\ldots$ & 1 & 25 & $-20 * *$ \\
\hline Andrews & 1992 & September & 95 & 86 & $\ldots$ & 26 & 43 & $\ldots$ & 16 & $\ldots$ & 11 & 53 & -27 \\
\hline Andrews & 1993 & August & 49 & 15 & $\ldots$ & 6 & 16 & 24 & 10 & $\ldots$ & 10 & 30 & $-23 *$ \\
\hline Andrews & 1993 & September & 95 & 69 & $\ldots$ & 39 & 73 & 78 & 54 & $\ldots$ & 37 & 66 & $-27 *$ \\
\hline \multicolumn{14}{|l|}{$\mathrm{FR} 1141 \times \mathrm{B} 37 \mathrm{HtN}$} \\
\hline Urbana & 1992 & Aug.-Sept. & 43 & 18 & 25 & 15 & 13 & 16 & 6 & 6 & 1 & 22 & -7 \\
\hline Urbana & 1993 & August & 23 & 13 & 14 & 4 & 10 & 11 & 4 & 5 & 2 & 13 & $-9 *$ \\
\hline Urbana & 1993 & September & 95 & 92 & 92 & 70 & 85 & 88 & 72 & 68 & 73 & 84 & -14 \\
\hline Andrews & 1992 & August & 70 & 31 & $\ldots$ & 6 & 14 & $\ldots$ & 5 & $\ldots$ & 3 & 37 & $-30 *$ \\
\hline Andrews & 1992 & September & 95 & 93 & $\ldots$ & 68 & 72 & $\ldots$ & 31 & $\ldots$ & 15 & 55 & 13 \\
\hline Andrews & 1993 & August & 82 & 46 & $\ldots$ & 9 & 23 & $\ldots$ & 9 & $\ldots$ & 9 & 45 & $-36 *$ \\
\hline Andrews & 1993 & September & 95 & 95 & $\ldots$ & 62 & 85 & $\ldots$ & 62 & $\ldots$ & 40 & 68 & -5 \\
\hline \multicolumn{14}{|l|}{ FR1141 × DS:74:1071 } \\
\hline Urbana & 1992 & Aug.-Sept. & 40 & 22 & 27 & 16 & 20 & 21 & 14 & 15 & 2 & 21 & -5 \\
\hline Urbana & 1993 & August & 20 & 14 & 13 & 9 & 10 & 10 & 8 & 9 & 5 & 13 & -4 \\
\hline Urbana & 1993 & September & 95 & 58 & 75 & 29 & 52 & 61 & 36 & 48 & 23 & 59 & $-30 *$ \\
\hline Andrews & 1992 & August & 66 & 37 & $\ldots$ & 12 & 26 & $\ldots$ & 9 & $\ldots$ & 4 & 35 & -24 \\
\hline Andrews & 1992 & September & 95 & 91 & $\ldots$ & 57 & 83 & $\ldots$ & 47 & $\ldots$ & 13 & 54 & 3 \\
\hline Andrews & 1993 & August & 86 & 44 & $\ldots$ & 6 & 16 & $\ldots$ & 8 & $\ldots$ & 5 & 46 & $-40 * *$ \\
\hline Andrews & 1993 & September & 95 & 94 & $\ldots$ & 47 & 78 & $\ldots$ & 62 & $\ldots$ & 47 & 71 & -24 \\
\hline
\end{tabular}

a Visual estimate of the percent leaf area blighted (necrotic).

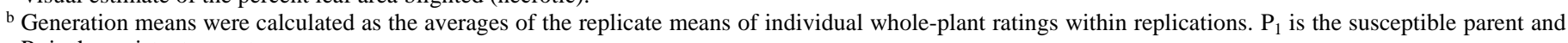
$\mathrm{P}_{2}$ is the resistant parent.

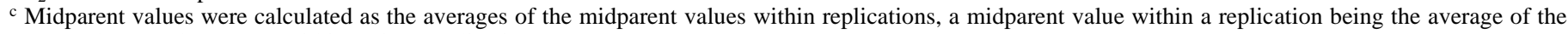
parental generation means within a given replication.

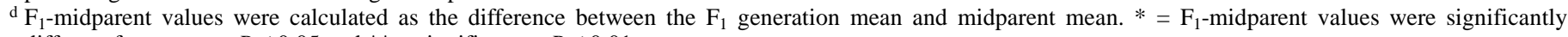
different from zero at $P \leq 0.05$ and $* *=$ significant at $P \leq 0.01$.

e Generation not evaluated. 
(34) using the equation $h^{2}$ (broad) $=\left(s_{F 2}^{2}-s_{P 1, P 2, F 1}^{2}\right) / s_{F 2}^{2}$, in which $s_{P 1, P 2, F 1}^{2}$ is a weighted average of the variances of the $\mathrm{P}_{1}, \mathrm{P}_{2}$, and $\mathrm{F}_{1}$ generations. Narrow-sense heritability estimates were calculated (47) using the equation $h^{2}$ (narrow) $=\left(2 s_{F 2}^{2}-\left[s_{B C P 1}^{2}+s_{B C P 2}^{2}\right]\right) / s_{F 2}^{2}$. Effective factor estimates were calculated using the equation of Mather and Jinks (29) substituting the additive variance estimate of Warner (47), in which $K=\left(P_{1}-P_{2}\right)^{2} /\left(8\left[2 s_{F 2}^{2}-\left\{s_{B C P 1}^{2}+s_{B C P 2}^{2}\right\}\right]\right)$.

\section{RESULTS}

In 1992, weather was favorable for gray leaf spot development at Urbana. Northern corn leaf spot caused by race 2 of Bipolaris zeicola (Stout) Shoem. and common rust caused by Puccinia sorghi Schwein also were prevalent. The development of these diseases was promoted by the overhead irrigation system used at this location. Rating disease required careful assessment so that only the quantity of tissue blighted by gray leaf spot was recorded. This lengthened the time necessary to do the ratings and, therefore, only one rating was possible. Mean severity for the susceptible parent FR1141 was about 40\% (Table 3). Conditions for disease development were ideal at Urbana in 1993 because of frequent rainfall including almost daily rain from late June to mid-July. Severity for FR1141 was about 20\% for the August rating and 95\% for the September rating. At Andrews in 1992, severity for FR1141 ranged from 62 to $70 \%$ in August and was 95\% for the September rating.
In 1993, the severity for FR1141 in August ranged from 82 to $90 \%$ for the first rating and was $95 \%$ for the second rating. Severity for B37 was usually less than for FR1141. Severities for the resistant parents in 1992 at Urbana were less than 5\%. For 061 at Andrews in 1992 and Andrews and Urbana in 1993, severity ranged from 2 to $5 \%$ for the early ratings and 23 to $68 \%$ at for later ratings. For B37HtN, from both the B37 $\times$ B $37 H t N$ and FR1141 $\times$ $\mathrm{B} 37 \mathrm{HtN}$ populations, severity ranged from 1 to $10 \%$ for the early ratings and from 11 to $73 \%$ for the later ratings. For DS:74:1071, severity was about $5 \%$ for the early ratings and 13 to $47 \%$ for the later ratings.

Effects of years, locations, and rating times. For the analyses of variance of the combined data from Andrews in 1992 and 1993 and from Andrews and Urbana in 1993, generation effects were significant $(P \leq 0.05$; Tables 4 and 5$)$. Effects of years were significant only for the $\mathrm{B} 37 \times \mathrm{B} 37 \mathrm{HtN}$ population, and effects of locations were significant only for the FR1141 $\times$ DS:74:1071 population. Effects of rating times were significant for all populations except B37 $\times \mathrm{B} 37 \mathrm{HtN}$ for the analysis of data from Andrews from 1992 and 1993. Generation $\times$ location interactions were significant for all populations. Generation $\times$ year interactions were significant only for the $\mathrm{B} 37 \times \mathrm{B} 37 \mathrm{HtN}$ population. Rating $\times$ generation interactions were significant for all populations for the data combined from both locations in 1993, but not for data combined from both years from the Andrews location. For three-factor interactions, all

TABLE 4. Analyses of variance for effects of locations and rating times on generation means of four populations evaluated for severity ${ }^{\mathrm{a}} \%$ ) of gray leaf spot at Urbana, IL, and Andrews, NC, in 1993

\begin{tabular}{|c|c|c|c|c|c|c|c|c|}
\hline \multirow[b]{3}{*}{ Source of variation } & \multicolumn{8}{|c|}{ Population } \\
\hline & \multicolumn{2}{|c|}{ FR $1141 \times 061$} & \multicolumn{2}{|c|}{$\mathrm{B} 37 \times \mathrm{B} 37 \mathrm{HtN}$} & \multicolumn{2}{|c|}{ FR1141 × B37HtN } & \multicolumn{2}{|c|}{ FR1141 × DS:74:1071 } \\
\hline & df & Mean square & df & Mean square & df & Mean square & df & Mean square \\
\hline Block (location) ${ }^{\mathrm{c}}$ & 2 & 353.98 & 2 & 4.68 & 2 & 243.90 & 2 & 12.00 \\
\hline Generation & 8 & $1,790.77 * *$ & 8 & $1,066.05^{* *}$ & 8 & $1,501.04 * *$ & 8 & $2,192.52 * *$ \\
\hline Generation $\times$ location & 7 & $537.71 * *$ & 6 & $157.57 * *$ & 5 & $462.35^{* *}$ & 5 & $248.35^{* *}$ \\
\hline Generation $\times$ block (location) ${ }^{\mathrm{c}}$ & 15 & 64.10 & 14 & 23.19 & 13 & 52.06 & 13 & 32.67 \\
\hline Rating $\times$ generation & 8 & $197.56^{*}$ & 8 & $147.24 * *$ & 8 & $134.27 * *$ & 8 & $198.92 * *$ \\
\hline Rating $\times$ generation $\times$ location & 7 & $207.72 *$ & 6 & $46.24 *$ & 5 & $166.16^{* *}$ & 5 & $639.92 * *$ \\
\hline Error & 17 & 74.28 & 16 & 14.36 & 15 & 30.37 & 15 & 22.62 \\
\hline Coefficient of variation & 16.6 & & 8.9 & & 11.5 & & 12.3 & \\
\hline
\end{tabular}

a Visual estimate of the percent leaf area blighted (necrotic).

b $*=$ significant at $P \leq 0.05$ and $* *=$ significant at $P \leq 0.01$.

${ }^{\mathrm{c}}$ Error term.

TABLE 5. Analyses of variance for the effects of years and rating times on the generation means of four populations evaluated for severity ${ }^{\mathrm{a}} \%$ ) of gray leaf spot at Andrews, NC, in 1992 and 1993

\begin{tabular}{|c|c|c|c|c|c|c|c|c|}
\hline \multirow[b]{3}{*}{ Source of variation } & \multicolumn{8}{|c|}{ Population } \\
\hline & \multicolumn{2}{|c|}{ FR1141 × 061} & \multicolumn{2}{|c|}{$\mathrm{B} 37 \times \mathrm{B} 37 \mathrm{HtN}$} & \multicolumn{2}{|c|}{$\mathrm{FR} 1141 \times \mathrm{B} 37 \mathrm{HtN}$} & \multicolumn{2}{|c|}{ FR1141 × DS:74:1071 } \\
\hline & df & Mean square & df & Mean square & df & Mean square & $\mathrm{df}$ & Mean square \\
\hline Block (year) ${ }^{\mathrm{c}}$ & 2 & 111.86 & 2 & 9.13 & 2 & 537.12 & 2 & 350.00 \\
\hline Generation $^{\mathrm{d}}$ & 7 & $3,987.85 * *$ & 6 & $3,295.72 *$ & 5 & $5,220.48 * *$ & 5 & $5,230.42 * *$ \\
\hline Generation $\times$ year & 5 & 23.54 & 5 & $436.73 * *$ & 5 & 99.98 & 5 & 198.68 \\
\hline Generation $\times$ block $($ year) & 12 & 9.03 & 11 & 34.66 & 10 & 75.91 & 10 & 59.88 \\
\hline Rating $\times$ generation ${ }^{\mathrm{f}}$ & 7 & 373.11 & 6 & 323.78 & 5 & 670.83 & 5 & 498.16 \\
\hline Rating $\times$ generation $\times$ year & 5 & $289.11^{* *}$ & 5 & $85.99 * *$ & 5 & $143.43^{*}$ & 5 & $175.69^{*}$ \\
\hline Error & 14 & 14.95 & 13 & 17.34 & 12 & 44.46 & 12 & 41.84 \\
\hline Coefficient of variation & 7.6 & & 11.4 & & 14.4 & & 13.8 & \\
\hline
\end{tabular}

a Visual estimate of the percent leaf area blighted (necrotic).

b * significant at $P \leq 0.05$ and $* *=$ significant at $P \leq 0.01$.

${ }^{\mathrm{c}}$ Error term.

${ }^{d}$ Tested using generation $\times$ year as an error term.

e Tested using rating $\times$ year as an error term.

${ }^{\mathrm{f}}$ Tested using rating $\times$ generation $\times$ year as an error term. 
populations had significant rating $\times$ generation $\times$ location and rating $\times$ generation $\times$ year interactions.

Results of combined generation mean analyses. For the analyses of combined data from Andrews in 1992 and 1993 and from

TABLE 6. Proportion of the variation among generation means $\left(R^{2}\right)$ accounted for by the genetic effect parameters of the simple additive-dominance models ${ }^{\mathrm{a}}$ used to analyze the generation means of four populations evaluated for severity ${ }^{b}$ (\%) of gray leaf spot at Urbana, IL, and Andrews, NC, in 1992 and 1993

\begin{tabular}{|c|c|c|c|c|c|}
\hline \multirow[b]{2}{*}{ Population } & \multirow[b]{2}{*}{ Effects } & \multicolumn{2}{|c|}{$\begin{array}{c}\text { Andrews in } 1992 \\
\text { and } 1993^{c}\end{array}$} & \multicolumn{2}{|c|}{$\begin{array}{c}\text { Urbana and } \\
\text { Andrews in } 1993^{c}\end{array}$} \\
\hline & & August & September & August & $\overline{\text { September }}$ \\
\hline \multirow[t]{2}{*}{ FR1141 × 061} & $d, h$ & $99.3^{* * \mathrm{~d}}$ & $78.7 * *$ & $99.0 *$ & $74.4 * *$ \\
\hline & Deviations & 0.7 & 21.3 & 1.0 & 25.6 \\
\hline \multirow[t]{2}{*}{$\mathrm{B} 37 \times \mathrm{B} 37 \mathrm{HtN}$} & $d, h$ & $99.1 * *$ & $95.2 * *$ & $91.3 * *$ & $76.6 * *$ \\
\hline & Deviations & 0.9 & 4.8 & 8.7 & 23.4 \\
\hline \multirow[t]{2}{*}{$\mathrm{FR} 1141 \times \mathrm{B} 37 \mathrm{HtN}$} & $d, h$ & $99.2 * *$ & $92.7 * *$ & $99.9 *$ & $84.0 *$ \\
\hline & Deviations & 0.7 & 7.3 & 0.1 & 16.0 \\
\hline \multirow[t]{2}{*}{ FR1141 × DS:74:1071 } & $d, h$ & $99.5^{* * *}$ & $84.3 * *$ & 98.5 & $92.6 * *$ \\
\hline & Deviations & 0.5 & 15.7 & 1.5 & 7.4 \\
\hline
\end{tabular}

a The genetic effect parameters of the equation $Y=m+c y+a_{1} x_{(1992)}+a_{2} x_{(1993)}+$ $b_{1} d+b_{2} h$ describing the pooled additive and dominance genetic effects on the generation means, in which $Y=$ generation mean, $m=$ midparent and intercept value, $y=$ year effect, $x_{(1992)}=$ block effect in 1992, $x_{(1993)}=$ block effect in 1993 (blocks were nested within years), $d=$ pooled additive effects (pooled effects of homozygous loci), and $h=$ pooled dominance effects (pooled effects of heterozygous loci) for the means from Andrews in 1992 and 1993; or the equation $Y=m+c l+a_{1} x_{\text {(Urbana) }}+a_{2} x_{\text {(Andrews) }}+b_{1} d+b_{2} h$, in which $l=$ location effect, $x_{\text {(Urbana) }}=$ block effect in Urbana, and $x_{\text {(Andrews) }}=$ block effect in Andrews (blocks were nested within years) for the means from Urbana and Andrews in 1993.

b Visual estimate of the percent leaf area blighted (necrotic).

c Analyses were of combined data from Andrews in 1992 and 1993 and Urbana in 1993 using means of generations common to the year or location combinations.

$\mathrm{d} *=$ significant at $P \leq 0.05$ and $* *=$ significant at $P \leq 0.01$.
Urbana and Andrews in 1993, data were analyzed separately for the different rating times because of the potential for interactions with maturity indicated by the analyses of variance (Table 4). This resulted in four analyses for each population. All analyses indicated that the simple additive-dominance model was adequate (Table 6). All analyses had normally distributed residuals except for the B37 $\times$ B37HtN population at Urbana and Andrews in 1993 at the first rating.

Parameter estimates for additive effects $(d)$ were significant $(P \leq 0.05)$ for all analyses (Table 7). The B37 $\times$ B $37 H t N$ population had significant estimates for dominance effects $(h)$ for all analyses. The $061 \times$ FR1141 and FR1141 $\times$ B37HtN populations had sigificant estimates of $h$ for the early ratings, but not for the late ratings. The FR1141 $\times$ DS:74:1071 population had three of four analyses with significant estimates of $h$. All significant estimates of $h$ were negative, and most were nearly as large or larger than their respective $d$ estimates.

Results of generation mean analyses for individual years, locations, and ratings. There were many interactions with generations indicated by the analyses of variance (Tables 4 and 5), and it was considered important to determine if there would be differences in the results in different environments and at different ratings. Therefore, data from individual years, locations, and ratings were analyzed. Populations had two to four analyses that indicated significant deviations $(P \leq 0.05)$ from the additive-dominance model (Table 8), for a total of 11 analyses with significant deviations. The B37 $\times$ B37HtN population had the most. At Urbana in 1992 and in 1993 at the early rating, the analyses indicated no significant deviations from the additive-dominance model for any of the populations evaluated. There were insufficient degrees of freedom to test deviations from the model that included digenic interaction parameters in 5 of the 11 analyses that had significant deviations from the additive-dominance model. Of the six that had sufficient

TABLE 7. Least squares estimates of the parameters of the simple additive-dominance models ${ }^{\mathrm{a}}$ used to analyze the generation means of four populations evaluated for severity ${ }^{\mathrm{b}}(\%)$ of gray leaf spot at Urbana, IL, and Andrews, NC, in 1992 and 1993

\begin{tabular}{|c|c|c|c|c|c|c|}
\hline \multirow[b]{2}{*}{ Population } & \multirow[b]{2}{*}{ Effects } & \multicolumn{2}{|c|}{ Andrews in 1992 and $1993^{c}$} & \multirow[b]{2}{*}{ Effects } & \multicolumn{2}{|c|}{ Urbana and Andrews in $1993^{c}$} \\
\hline & & August & September & & August & September \\
\hline \multirow[t]{6}{*}{ FR1141 × 061} & $m$ & $31.1 * * \mathrm{~d}$ & $70.6^{* *}$ & $m$ & $23.7 * *$ & $84.8 * *$ \\
\hline & $y$ & 3.1 & $-10.6^{* *}$ & $l$ & $-7.1 *$ & 2.2 \\
\hline & $x_{(1992)}$ & -1.5 & -3.8 & $x_{\text {(Urbana) }}$ & 0.0 & $-8.4^{*}$ \\
\hline & $x_{(1993)}$ & 0.8 & 2.0 & $x_{\text {(Andrews) }}$ & 1.1 & 1.6 \\
\hline & $d$ & $36.3^{* *} *$ & $30.2 * *$ & $d$ & $26.5^{* *} *$ & $18.7 * *$ \\
\hline & $h$ & $-35.0 * *$ & -11.9 & $h$ & $-25.2 * *$ & -8.4 \\
\hline \multirow[t]{6}{*}{$\mathrm{B} 37 \times \mathrm{B} 37 \mathrm{HtN}$} & $m$ & $26.4 * *$ & $63.3 * *$ & $m$ & $19.8 * *$ & $80.9 * *$ \\
\hline & $y$ & -0.6 & $-7.4^{*}$ & $l$ & $-5.0 * *$ & $6.9 * *$ \\
\hline & $x_{(1992)}$ & -0.8 & -0.4 & $x_{\text {(Urbana) }}$ & -0.1 & 0.4 \\
\hline & $x_{(1993)}$ & 1.0 & -2.3 & $x_{\text {(Andrews) }}$ & 0.6 & -1.8 \\
\hline & $d$ & $20.6^{* *}$ & $36.8 * *$ & $d$ & $12.2 * *$ & $17.8^{* *}$ \\
\hline & $h$ & $-22.4 * *$ & $-23.0 * *$ & $h$ & $-16.3 * *$ & $-26.6^{* *}$ \\
\hline \multirow[t]{6}{*}{$\mathrm{FR} 1141 \times \mathrm{B} 37 \mathrm{HtN}$} & $m$ & $39.8 * *$ & $64.8 * *$ & $m$ & $28.9 * *$ & $79.7 * *$ \\
\hline & $y$ & $-3.9 * *$ & -5.4 & $l$ & $-10.2 * *$ & 3.9 \\
\hline & $x_{(1992)}$ & $-3.5^{*}$ & -6.4 & $x_{\text {(Urbana) }}$ & -0.4 & 1.6 \\
\hline & $x_{(1993)}$ & -2.6 & -6.4 & $x_{\text {(Andrews) }}$ & -2.6 & -6.4 \\
\hline & $d$ & $34.3 * *$ & $36.2 * *$ & $d$ & $23.3^{* *} *$ & $20.4^{* *} *$ \\
\hline & $h$ & $-34.1 * *$ & 7.3 & $h$ & $-22.9 * *$ & -5.9 \\
\hline \multirow[t]{6}{*}{ FR1141 × DS:74:1071 } & $m$ & $40.0 * *$ & $69.1^{* *}$ & $m$ & $28.5^{* *}$ & $69.1 * *$ \\
\hline & $y$ & -0.9 & -3.2 & $l$ & $-8.2^{*}$ & $-11.0 * *$ \\
\hline & $x_{(1992)}$ & $-4.4^{*}$ & -6.2 & $x_{\text {(Urbana) }}$ & 1.4 & -1.0 \\
\hline & $x_{(1993)}$ & 0.0 & -1.7 & $x_{\text {(Andrews) }}$ & 0.0 & -1.7 \\
\hline & $d$ & $35.0 * *$ & $33.6^{* * *}$ & $d$ & $23.4 * *$ & $29.3^{* *}$ \\
\hline & $h$ & $-32.2 * *$ & -3.9 & $h$ & $-22.3 *$ & $-22.5 * *$ \\
\hline
\end{tabular}

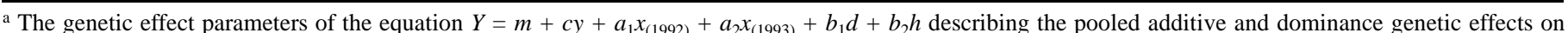
the generation means, in which $Y=$ generation mean, $m=$ midparent and intercept value, $y=$ year effect, $x_{(1992)}=$ block effect in 1992, $x_{(1993)}=$ block effect in 1993 (blocks were nested within years), $d=$ pooled additive effects (pooled effects of homozygous loci), and $h=$ pooled dominance effects (pooled effects of heterozygous loci) for the means from Andrews in 1992 and 1993, or the equation $Y=m+c l+a_{1} x_{\text {(Urbana) }}+a_{2} x_{(\text {Andrews })}+b_{1} d+b_{2} h$, in which $l=1$ location effect, $x_{\text {(Urbana) }}=$ block effect in Urbana, and $x_{\text {(Andrews) }}=$ block effect in Andrews (blocks were nested within locations) for the means from Urbana and Andrews in 1993. There were no significant deviations from the additive-dominance models; therefore, it was not necessary to use the digenic interaction model.

b Visual estimate of the percent leaf area blighted (necrotic).

c Analyses were of combined data from Andrews in 1992 and 1993 and Urbana in 1993 using means of generations common to the year or location combinations.

d * $=$ significant at $P \leq 0.05$ and $* *=$ significant at $P \leq 0.01$. 
degrees of freedom, two of six (FR1141 $\times 061$ in 1993 at Urbana at the late rating and $\mathrm{B} 37 \times \mathrm{B} 37 \mathrm{HtN}$ in 1993 at Andrews at the early rating) had significant deviations from the digenic interaction model (Table 9).

The FR1141 $\times$ DS:74:1071 population had residuals that deviated significantly $(P \leq 0.05)$ from normality at the early rating at Urbana in 1993 . The FR $1141 \times$ B37HtN population had residuals that deviated significantly from normality at the early rating at Andrews in 1993. All other analyses had normally distributed residuals.

All populations had significant $(P \leq 0.05)$ additive genetic effects (Table 10). Of 28 analyses, 11 had significant dominance genetic effects. The FR1141 $\times 061$ population had five of seven analyses in which the $h$ estimates were significant. Of these, three were at early ratings; $\mathrm{B} 37 \times \mathrm{B} 37 \mathrm{HtN}$ had two of seven, both at early ratings; FR1141 $\times \mathrm{B} 37 \mathrm{HtN}$ had two of seven, at the same year, locations, and rating as the $\mathrm{B} 37 \times \mathrm{B} 37 \mathrm{HtN}$ population; and FR1141 $\times$ DS:74:1071 had two of seven. All significant estimates of $h$ were negative. Most significant estimates of $h$ were nearly as large or larger than their respective $d$ estimates.

For the 11 analyses from individual years, locations, and ratings with significant deviations from the additive-dominance model, only two populations had any repeatability in the significance of their digenic interaction parameter estimates. B37 $\times$ B $37 H t N$ had significant dominance $\times$ dominance interactions $(l)$ for three of four analyses and significant additive $\times$ dominance interactions $(j)$ for two of four analyses. The FR1141 $\times$ DS:74:1071 population had significant additive $\times$ additive interactions $(i)$ for two of two analyses.

$\mathbf{F}_{1}$-midparent test. There were significant $(P \leq 0.05)$ differences between $F_{1}$ means and mean midparent values for 14 of 28 analyses (Table 3). The number of significant $F_{1}$-midparent values ranged from two of seven for the FR1141 $\times$ DS:74:1071 population to five of seven for the $\mathrm{B} 37 \times \mathrm{B} 37 \mathrm{HtN}$ population. All significant deviations of the $F_{1}$ means from the midparent means were negative and were associated with significant dominance effects or deviations from the additive-dominance model. Five analyses with significant dominance or deviations from the additive-dominance model were not associated with significant $\mathrm{F}_{1}$-midparent values.

Heritability and effective factor estimates. Broad-sense heritability estimates were between 0.50 and 1.00 for five of seven analyses for all populations except the FR1141 $\times$ B37HtN population, which had three of seven (Table 11). Narrow-sense heritability estimates were between 0.50 and 1.00 for four analyses from the FR1141 $\times$ B37HtN population, for none of the analyses from the $\mathrm{B} 37 \times \mathrm{B} 37 \mathrm{HtN}$ population, and for three analyses from each of the other populations. Effective factor estimates were less than 5.00 for three to five analyses per population. In some cases, the populations had negative heritability and effective factor estimates.

TABLE 8. Proportion of the variation among generation means $\left(R^{2}\right)$ accounted for by the genetic effect parameters of the simple additive-dominance model ${ }^{\mathrm{a}}$ used to analyze the generation means of four populations evaluated for severity (\%) of gray leaf spot at Urbana, IL, and Andrews, NC, in 1992 and 1993

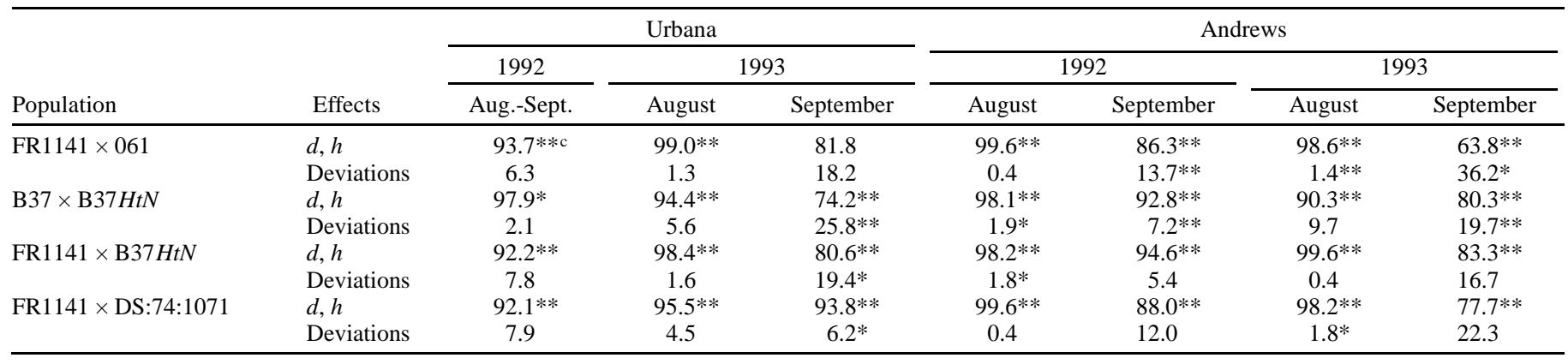

a The genetic effect parameters of the equation $Y=m+a x+b_{1} d+b_{2} h$ describing the pooled additive and dominance genetic effects on the generation means, in which $Y=$ generation mean, $m=$ midparent and intercept value, $x=$ block effect, $d=$ pooled additive effects (pooled effects of homozygous loci), and $h=$ pooled dominance effects (pooled effects of heterozygous loci).

$\mathrm{b}$ Visual estimate of the percent leaf area blighted (necrotic).

c * = significant at $P \leq 0.05$ and $* *=$ significant at $P \leq 0.01$.

TABLE 9. Proportion of the variation among generation means $\left(R^{2}\right)$ accounted for by the genetic effect parameters of the digenic interaction model ${ }^{\mathrm{a}}$ used to analyze the generation means of four populations evaluated for severity ${ }^{\mathrm{b}}(\%)$ of gray leaf spot in which there were significant deviations from the additivedominance model at Urbana, IL, and Andrews, NC, in 1992 and 1993

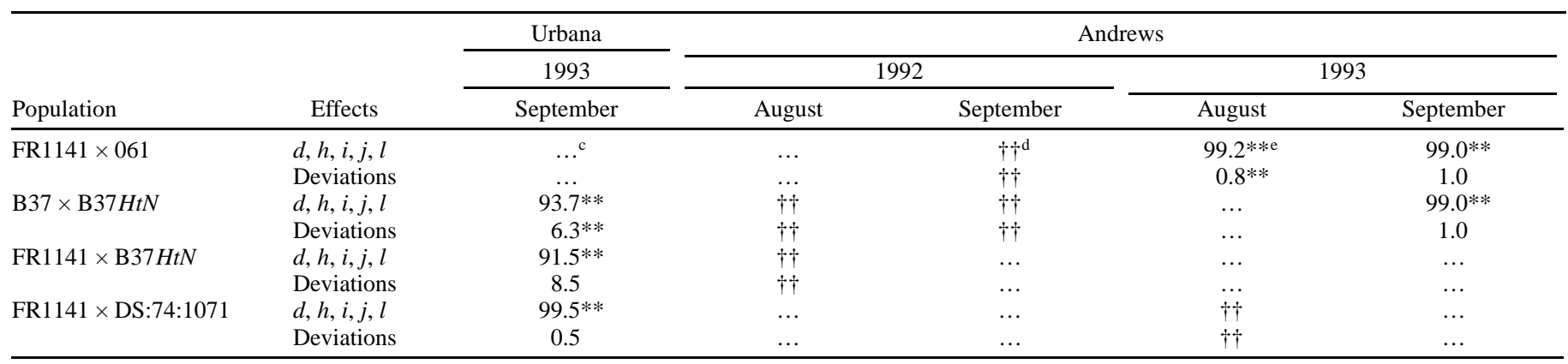

a The genetic effect parameters of the equation $Y=m+a x+b_{1} d+b_{2} h+b_{3} i+b_{4} j+b_{5} l$ describing the pooled additive, dominance, and epistatic genetic effects on the generation means, in which $Y=$ generation mean, $m=$ mean of the $\mathrm{F}_{\infty}$ generation (mean of the inbreds derived from a cross of the two parents without selection) and intercept value, $x=$ block effect, $d=$ pooled additive effects (pooled effects of homozygous loci), $h=$ pooled dominance effects (pooled effects of heterozygous loci), $i=$ additive $\times$ additive (homozygote $\times$ homozygote) interaction effects, $j=$ additive $\times$ dominance (homozygote $\times$ heterozygote) interaction effects, and $l=$ dominance $\times$ dominance (heterozygote $\times$ heterozygote) interaction effects.

${ }^{b}$ Visual estimate of the percent leaf area blighted (necrotic).

c $\ldots=$ no significant deviations from the additive-dominance model $\left(Y=m+a x+b_{1} d+b_{2} h\right)$; therefore, it was not necessary to test the model that included digenic interactions.

$\mathrm{d}+\dagger=$ deviations from the additive-dominance model were significant, but there were insufficient degrees of freedom to test deviations from the model that included digenic interactions for significance.

e $*=$ significant at $P \leq 0.05$ and $* *=$ significant at $P \leq 0.01$. 


\section{DISCUSSION}

The inheritance of resistance to gray leaf spot from the populations studied can be described by a simple additive-dominance model as indicated by the combined analyses. When deviations from the additive-dominance model are not significant, the parameter estimates from the additive-dominance model are used to estimate the pooled additive and pooled dominance effects $(19,29)$. When dominance is significant, the potency of the dominance is determined by the magnitude of the dominance parameter estimate relative to the magnitude of the additive parameter estimate (29). Dominance was significant for analyses of combined data from all populations for the early ratings. These parameter estimates were negative and nearly as large or larger than their respective additive effects estimates. This indicates that the dominance was for resistance and that the pooled effects of heterozygous loci for resistance were as potent as the pooled effects of homozygous loci. The lack of significant dominance for FR1141 $\times 061$ and FR1141 $\times$ B37HtN at the late rating times indicates that gene action present at the first rating may no longer have been functioning by the late rating. The means for the resistant parents for these populations were much higher by the late ratings (Table 3 ).

The results for the individual analyses were not as uniform as the results of the combined analyses. The simple additive-dominance model was adequate for most analyses from individual years, locations, and ratings for all populations except for $\mathrm{B} 37 \times \mathrm{B} 37 \mathrm{HtN}$, which had more analyses with deviations. The results for FR1141 $\times$ 061 were consistent with the combined analyses, with dominance tending to be significant at early rating times, but not significant for two of three late ratings. For the other populations, the results were not consistent with the results of the combined analyses. Most analyses with deviations from the simple additive-dominance model were from late ratings, indicating the possibility of a maturity effect. Also, the genetic interaction parameter estimates from the digenic interaction model lacked uniformity except for the B37 $\times$ B37HtN and FR1141 $\times$ DS:74:1071 populations.

The difference in results between the individual and combined analyses for model testing may be due to the use of a different error term for the test. The combined analyses used either the generation $\times$ year or the generation $\times$ location interactions as an estimate of the generation $\times$ environment interaction for an error term. For the individual analyses, the random error term provided by SAS (the generation $\times$ block interaction) was used. This interaction did not take into account the differences in gene expression in different environments. It could be that the interactions detected with the digenic interaction model were due to interactions of resistance genes with genes for other traits that affected the expression of the resistance genes in a particular environment. This possibility is indicated by the general lack of consistency in the type of interactions detected. One possibility is the interaction of maturity with resistance, since later-maturing lines tend to be more resistant than early-maturing lines (6), and plants within the segregating generations were segregating for maturity as well as resistance. The more uniform results for the parameter estimates from the combined analyses may be due to the larger number of data points used for estimating genetic effects.

Mather and Jinks (29) give coefficients for the equation used in generation mean analysis for the cases in which the genes for the

TABLE 10. Least squares estimates of the parameters of the model ${ }^{\mathrm{a}}$ used in generation mean analysis of four populations evaluated for severity ${ }^{\mathrm{b}}(\%)$ of gray leaf spot at Urbana, IL, and Andrews, NC, in 1992 and 1993

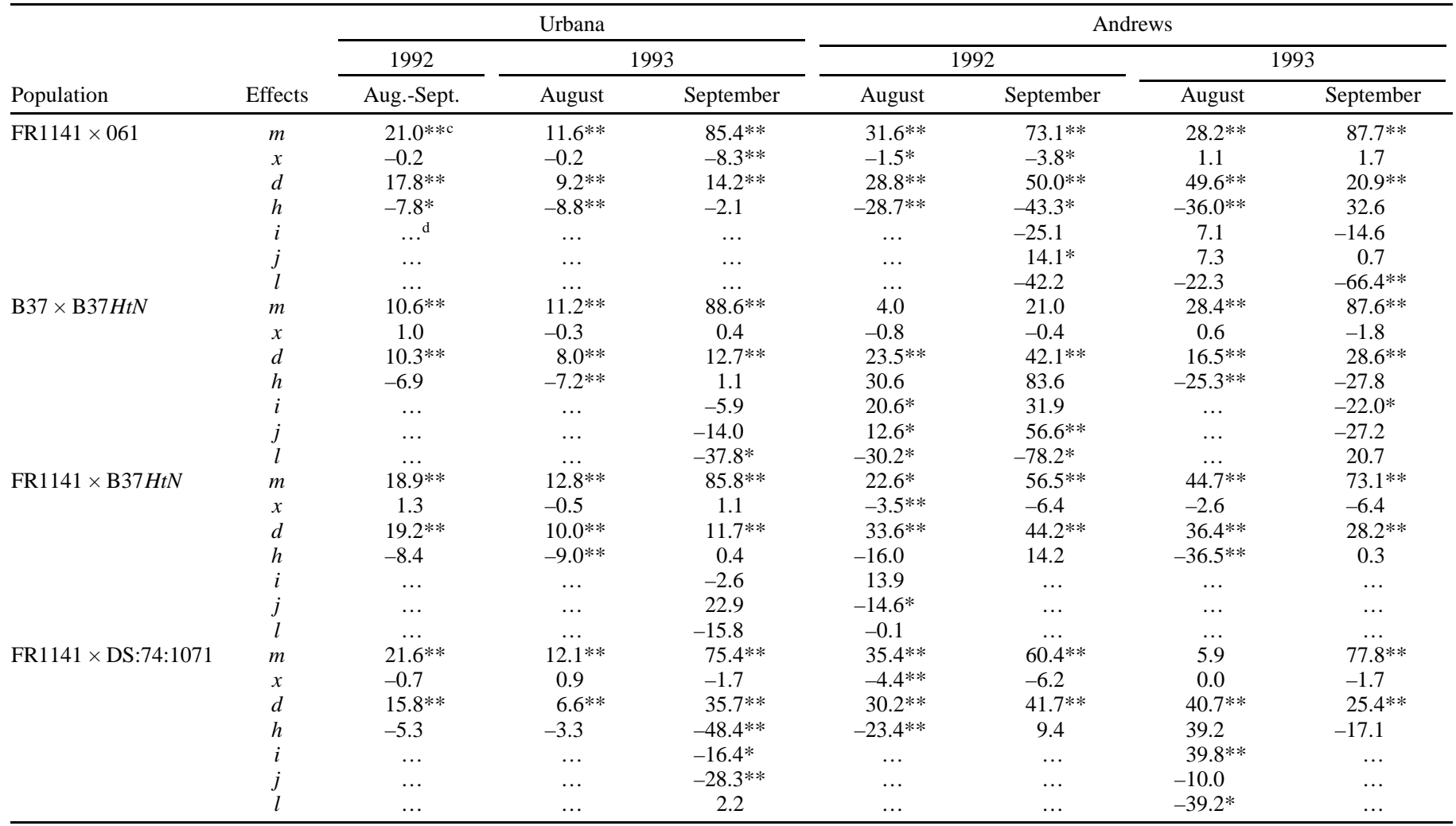

a The parameters of the equation $Y=m+a x+b_{1} d+b_{2} h+b_{3} i+b_{4 j}+b_{5} l$ describing the pooled additive, dominance, and epistatic genetic effects on the generation means, in which $Y=$ generation mean, $m=$ midparent (additive-dominance model) or mean of the $\mathrm{F}_{\infty}$ generation (mean of the inbreds derived from a cross of the two parents without selection) (digenic interaction model) and intercept value, $x=$ block effect, $d=$ pooled additive effects (pooled effects of homozygous loci), $h=$ pooled dominance effects (pooled effects of heterozygous loci), $i=$ additive $\times$ additive (homozygote $\times$ homozygote) interaction effects, $j=$ additive $\times$ dominance (homozygote $\times$ heterozygote) interaction effects, and $l=$ dominance $\times$ dominance (heterozygote $\times$ heterozygote) interaction effects.

${ }^{\mathrm{b}}$ Visual estimate of the percent leaf area blighted (necrotic).

c * = significant at $P \leq 0.05$ and $* *=$ significant at $P \leq 0.01$.

d $\ldots=$ no significant deviations from the additive-dominance model $\left(Y=m+a x+b_{1} d+b_{2} h\right)$; therefore, it was not necessary to use the digenic interaction model. 
trait being studied are associated, or concentrated, in one of the two parents and also for the case in which the genes are dispersed, or distributed, evenly between the two parents. However, they point out that, typically, genes for most quantitative traits are not absolutely associated in one of the parents. This seems particularly relevant to a discussion of disease resistance in which resistance and susceptibility exist in a continuum and few lines are likely to be found that are completely resistant or susceptible. For these experiments, the coefficients used were for the case in which the genes are associated. The inbred line B37 is not as susceptible to gray leaf spot as FR1141, which may explain why the results were different for this population as compared with the FR1141 $\times$ B37HtN population. However, the means of the susceptible parents from this population and the other populations were usually much larger than their resistant parents, so the coefficients for the associated condition were considered the most appropriate. Another limitation of generation mean analysis is that the effect of genes that oppose each other cannot be detected (29). It could be that effects of some genes could be detected in the $\mathrm{B} 37 \times \mathrm{B} 37 \mathrm{HtN}$ population that could not be detected in the FR1141 $\times$ B $37 H t N$ population.

Hayman (19) and Mather and Jinks (29) used weighted means to obtain least squares estimates of the parameters and to test their models using chi-square tests. The weights used were the inverses of the variances of the means of the generations. For these data, this method was not possible, because many of the genetically homogeneous generations had little or no variance, which resulted in extremely large or undefined weights. The resistant parents and $\mathrm{F}_{1}$ generations sometimes had little or no variance at the early rating times, and the susceptible parents sometimes had little or no variance at the later rating times. Therefore, unweighted means were used in the analysis. Since the chi-square test could not be done, the models were tested for adequacy by analysis of variance, which has been used in previous studies $(7,8,23,30,45)$.

Results from generation mean analysis depend on the scale used to measure the trait (29); therefore, different scales may give dif- ferent results. Because the phenotypic effects of individual genes cannot be determined for quantitative traits, there is no genetic basis for claiming one scale is better than another, although Mather and Jinks (29) recommend finding a rating scale for which the additive-dominance model is adequate. Transforming the data is the equivalent of measuring the phenotype on a different rating scale. If the data do not fit the simple additive-dominance model, Mather and Jinks recommend transforming the data so that it fits the additive-dominance model. However, if the data fit the additive-dominance model, they recommend caution if the data is to be transformed for statistical reasons. In such a case, transformed data may not fit the model as well as the untransformed data. The arcsine transformation is recommended for data expressed as percentages (41). For these experiments, the Shapiro-Wilk test indicated that the residuals from most of the regression analyses were normally distributed. The analyses with residuals that were not normally distributed had no significant deviations from the additivedominance model. Therefore, the untransformed data from these experiments were considered adequate for analysis.

Analysis of variance demonstrated significant effects from rating $\times$ generation interactions, year $\times$ rating $\times$ generation interactions, and location $\times$ rating $\times$ generations interactions. This indicates that differences between generation means for certain populations studied were affected by rating and by the rating within different environments. If Mendelian ratios can be found in the segregating generations, the ideal rating time would be when this segregation is clearest in the data. There were no apparent ratios in the data from these experiments. For generation mean analysis with these populations, rating disease in August may be beneficial, because early rating times have the advantage of less interference from maturity and senescence. This is particularly true of FR1141 $\times 061$ and FR1141 $\times$ B37HtN populations, which had significant dominance effects at the early but not at the late ratings. However, a later rating would more closely reflect the total damage to the leaf tissue for the entire growing season. Perhaps the most practical rating time

TABLE 11. Estimates of broad- and narrow-sense heritabilities and number of effective factors for four populations evaluated for severity $(\%)$ of gray leaf spot at Urbana, IL, and Andrews, NC, in 1992 and 1993

\begin{tabular}{|c|c|c|c|c|c|c|}
\hline Population & Location & Year & Rating time & Broad-sense heritability estimate $^{b}$ & Narrow-sense heritability estimate $^{c}$ & Effective factor estimate $^{\mathrm{d}}$ \\
\hline \multirow{5}{*}{ FR1141 × 061} & Urbana & 1992 & Aug.-Sept. & 0.45 & 1.26 & 1.48 \\
\hline & Urbana & 1993 & September & 0.50 & -0.54 & -1.55 \\
\hline & Andrews & 1992 & September & 0.66 & 0.69 & 1.29 \\
\hline & Andrews & 1993 & August & 0.94 & 0.91 & 2.10 \\
\hline & Andrews & 1993 & September & -1.21 & -2.06 & -0.62 \\
\hline \multirow[t]{5}{*}{$\mathrm{B} 37 \times \mathrm{B} 37 \mathrm{HtN}$} & Urbana & 1992 & Aug.-Sept. & 0.13 & 0.12 & 32.64 \\
\hline & Andrews & 1992 & August & 0.74 & -0.53 & -3.47 \\
\hline & Andrews & 1992 & September & 0.94 & 1.48 & 0.54 \\
\hline & Andrews & 1993 & August & 0.73 & 1.11 & 0.60 \\
\hline & Andrews & 1993 & September & 0.81 & -0.06 & -10.79 \\
\hline \multirow[t]{3}{*}{ FR1141 × B37HtN } & Urbana & 1992 & Aug.-Sept. & 0.46 & 0.86 & 5.43 \\
\hline & Urbana & 1993 & August & 0.85 & 1.19 & 1.69 \\
\hline & Urbana & 1993 & September & -0.39 & 0.58 & 0.68 \\
\hline \multirow{6}{*}{ FR1141 × DS:74:1071 } & Urbana & 1993 & August & 0.19 & 0.35 & 4.52 \\
\hline & Urbana & 1993 & September & 0.95 & 0.80 & 2.30 \\
\hline & Andrews & 1992 & August & 0.72 & 0.82 & 2.96 \\
\hline & Andrews & 1922 & September & 0.62 & -0.89 & -3.18 \\
\hline & Andrews & 1993 & August & 0.86 & -1.34 & -2.68 \\
\hline & Andrews & 1993 & September & 0.58 & 0.46 & 1.39 \\
\hline
\end{tabular}

\footnotetext{
${ }^{a}$ Visual estimate of the percent leaf area blighted (necrotic).

${ }^{\mathrm{b}}$ Broad-sense heritabilities were estimated using the equation $h^{2}$ (broad) $=\left(s_{F 2}^{2}-s_{P 1, P 2, F 1}^{2}\right) / s_{F 2}^{2}$.

${ }^{\mathrm{c}}$ Narrow-sense heritabilities were estimated using the equation $h^{2}$ (narrow) $=\left(2 s^{2}{ }_{F 2}-\left[s_{B C P 1}^{2}+s_{B C P 2}^{2}\right]\right) / s^{2}{ }_{F 2}$.

${ }^{\mathrm{d}}$ Effective factor estimates were calculated using the equation $K=\left(P_{1}-P_{2}\right)^{2} /\left(8\left[2 s^{2}{ }_{F 2}-\left\{s_{B C P 1}^{2}+s_{B C P 2}^{2}\right\}\right]\right)$.
} 
might be at the point in the growing season when an increase in damage to the leaf tissue would not result in further yield loss. At this time, data for the analysis could be collected, and it could be determined if there were individuals within the segregating generations with adequate levels of resistance. From this information, the inheritance of resistance could be determined, and it would be possible to assess whether adequate resistance can be transferred from the source of resistance being studied.

Some heritability estimates were negative or exceeded one. This was particularly true of the $\mathrm{B} 37 \times \mathrm{B} 37 \mathrm{HtN}$ population. Also, some effective factor estimates were negative or very large. When the narrow-sense heritability estimates were negative, so were their respective effective factor estimates. This was due to the use of a common additive variance estimate. The estimation of the narrowsense heritabilities, the number of effective factors, and the additive variance estimates used in these calculations are based on the assumption of no epistasis or linkage $(29,47)$. The assumption of no epistasis is clearly violated by these populations for various analyses from individual years, locations, and ratings, particularly the $\mathrm{B} 37 \times \mathrm{B} 37 \mathrm{HtN}$ population. These negative heritability and effective factor estimates, and heritability estimates that exceeded one, could be due to poor variance estimates due to epistasis, sampling error, environmental effects, or, for the later rating times, the effects of maturity. The mostly low estimates of effective factors and the mostly high heritability estimates indicate that resistance is polygenic, and selection for resistance to gray leaf spot should be effective in these populations.

The results indicate that resistance from the populations evaluated is due to more than one gene and has dominance. However, the results of analyses of data from individual years, locations, and ratings indicate that expression of resistance is environmentally dependent. Most inheritance studies on resistance to gray leaf spot have indicated additive inheritance, with a few studies reporting dominance. The resistant parents for the populations in this study were initially selected on the basis of hybrid performance in crosses with a susceptible parent; therefore, it is not surprising that they all have dominance for resistance. The presence of dominance for resistance in these populations indicates that the resistance from these inbreds can contribute significant resistance to hybrids.

The resistant inbred lines studied in these experiments are being used in a breeding program at the University of Illinois to transfer gray leaf spot resistance to B73-type germ plasm. Breeding programs using this kind of resistance need to evaluate sufficient numbers of individuals to obtain inbreds with all resistance genes. Based on the results of breeding efforts using these lines (data not shown), the resistance in the inbred 061 has been the easiest to transfer. Selections from the $\mathrm{BCP}_{1} \mathrm{~S}_{1}$ families of the FR1141 $\times 061$ population used in these experiments have yielded inbreds that have produced hybrids with levels of resistance that are sufficient for Andrews, NC, and high yield when crossed to a Mo17-type inbred line. Attempts to transfer resistance from the other resistant lines in these experiments have not been as successful. The difficulty in transferring resistance from the other sources of resistance may be due to the number of genes involved, difficulty in selecting the best genotypes, the evaluation of an insufficient number of $\mathrm{BCP}_{1} \mathrm{~S}_{1}$ families, or a combination of these factors. Screening more families from the other populations in these experiments may yield useful material. Continuing breeding efforts involving the use of these lines as sources of resistance will involve transfer of resistance to both B73-type and Mo17-type germ plasm.

\section{ACKNOWLEDGMENTS}

Research support was provided by Illinois Foundation Seeds, Inc. Plots at Andrews, NC, were provided and planted by Pioneer Hi-Bred International, Inc. A portion of the research done by S. T. Coates in partial fulfillment of the requirements for the Ph.D. degree in the graduate college of the University of Illinois, Urbana.

\section{LITERATURE CITED}

1. Anonymous. 1989. 1989 Seed List, Zea mays L. North Central Regional Plant Introduction Station, Ames, IA.

2. Arndt, C. H. 1943. Fungi affecting corn stalks, leaves and sheaths in northwestern South Carolina in 1943. Plant Dis. Rep. 27:562.

3. Bair, W., and Ayers, J. E. 1986. Variability in isolates of Cercospora zeae maydis. Phytopathology 76:129-132.

4. Beckman, P. M., and Payne, G. A. 1982. External growth, penetration, and development of Cercospora zeae-maydis in corn leaves. Phytopathology 72:810-815.

5. Beckman, P. M., and Payne, G. A. 1983. Cultural techniques and conditions influencing growth and sporulation of Cercospora zeae-maydis and lesion development in corn. Phytopathology 73:286-289.

6. Bubeck, D. M., Goodman, M. M., Beavis, W. D., and Grant, D. 1993. Quantitative trait loci controlling resistance to gray leaf spot in maize. Crop Sci. 33:838-847.

7. Carson, M. L., and Hooker, A. L. 1981. Inheritance of resistance to anthracnose leaf blight in five inbred lines of corn. Phytopathology 71:488-491.

8. Carson, M. L., and Hooker, A. L. 1981. Inheritance of resistance to stalk rot of corn caused by Colletotrichum graminicola. Phytopathology 71: 1190-1196.

9. Coates, S. T. 1989. The inheritance of resistance to Cercospora zeaemaydis in the maize inbred Mo18W. M.S. thesis. University of Delaware, Newark.

10. Coates, S. T. 1996. Inheritance of resistance to gray leaf spot of corn. $\mathrm{Ph} . \mathrm{D}$. dissertation. University of Illinois at Urbana-Champaign.

11. Coates, S. T., and White, D. G. 1994. Sources of resistance to gray leaf spot of corn. Plant Dis. 78:1153-1155.

12. de Nazareno, N. R. X., Lipps, P. E., and Madden, L. V. 1992. Survival of Cercospora zeae-maydis in corn residue in Ohio. Plant Dis. 76:560-563.

13. de Nazareno, N. R. X., Lipps, P. E., and Madden, L. V. 1993. Effect of levels of corn residue on the epidemiology of gray leaf spot of corn in Ohio. Plant Dis. 77:67-70.

14. Donahue, P. J., Stromberg, E. L., and Myers, S. L. 1991. Inheritance of reaction to gray leaf spot in a diallel cross of 14 maize inbreds. Crop Sci. 31:926-931.

15. Elwinger, G. F., Johnson, M. W., Hill, R. R., and Ayers, J. E. 1990. Inheritance of resistance to gray leaf spot of corn. Crop Sci. 30:350-358.

16. Freppon, J. T., Lipps, P. E., and Pratt, R. C. 1994. Characterization of the chlorotic lesion response by maize to Cercospora zeae-maydis. Plant Dis. 78:945-949.

17. Gevers, H. O., Lake, J. K., and Hohls, T. 1994. Diallel cross analysis of resistance to gray leaf spot in maize. Plant Dis. 78:379-383.

18. Graham, M. J., Hawk J. A., Carroll, R. B., Ayers, J. E., Lamkey, K. R., and Hallauer, A. R. 1993. Evaluation of Iowa stiff stalk synthetic for resistance to gray leaf spot. Plant Dis. 77:382-385.

19. Hayman, B. I. 1958. The separation of epistatic effects from additive and dominance variation in generation means. Heredity 12:371-390.

20. Henderson, C. B. 1980. Maize Research and Breeders Manual No. IX. Illinois Foundation Seeds Inc., Champaign, IL.

21. Hilty, J. W., Hadden, C. H., and Garden, F. T. 1979. Response of maize hybrids and inbred lines to gray leaf spot disease and the effects on yield in Tennessee. Plant Dis. Rep. 63:515-518.

22. Huff, C. A., Ayers, J. E., and Hill, R. R. 1988. Inheritance of resistance in corn (Zeae mays) to gray leaf spot. Phytopathology 78:790-794.

23. Hughes, G. R., and Hooker, A. L. 1971. Gene action conditioning resistance to northern leaf blight in maize. Crop Sci. 11:180-184.

24. Hyre, R. A. 1943. Cercospora zeae-maydis on corn in eastern Tennessee and Kentucky. Plant Dis. Rep. 27:553-554.

25. Kingsland, G. C. 1963. Cercospora leaf blight of corn: A case history of a local epiphytotic in South Carolina. Plant Dis. Rep. 47:724-725.

26. Latterell, F. M., and Rossi, A. E. 1983. Gray leaf spot of corn: A disease on the move. Plant Dis. 67:842-847.

27. Lehman, S. G. 1944. Corn leaf diseases observed in North Carolina in 1943. Plant Dis. Rep. 28:183-184.

28. Leonard, K. J. 1974. Foliar pathogens of corn in North Carolina. Plant Dis. Rep. 58:532-534.

29. Mather, K., and Jinks, J. L. 1982. Biometrical Genetics. 3rd ed. Chapman and Hall, London.

30. Moll, R. H., Thompson, D. L., and Harvey, P. H. 1963. A quantitative genetic study of the inheritance of resistance to brown spot (Physoderma maydis) of corn. Crop Sci. 3:389-391.

31. Neter, J., Wasserman, W., and Kutner, M. H. 1990. Applied Linear Statistical Models. 3rd ed. Richard D. Irwin, Inc., Homewood, IL.

32. Payne, G. A., Duncan, H. E., and Adkins, C. R. 1987. Influence of tillage on development of gray leaf spot and number of airborne conidia of Cercospora zeae-maydis. Plant Dis. 71:329-332.

33. Payne, G. A., and Waldron, J. K. 1983. Overwintering and spore release 
of Cercospora zeae-maydis in corn debris in North Carolina. Plant Dis. 67:87-89.

34. Poehlman, J. W., and Sleper, D. A. 1995. Breeding Field Crops. 4th ed. Iowa State University Press, Ames.

35. Roane, C. W. 1950. Observations on corn diseases in Virginia from 1947-1950. Plant Dis. Rep. 34:394-396.

36. Roane, C. W., Harrison, R. L., and Genter, C. F. 1974. Observations on gray leaf spot of maize in Virginia. Plant Dis. Rep. 58:456-459.

37. Rupe, J. C., Siegel, M. R., and Hartman, J. R. 1982. Influence of environment and plant maturity on gray leaf spot of corn caused by Cercospora zeae-maydis. Phytopathology 72:1587-1591.

38. Saghai Maroof, M. A., Van Scoyoc, S. W., Yu, Y. G., and Stromberg, E. L. 1993. Gray leaf spot disease of maize: Rating methodology and inbred line evaluation. Plant Dis. 77:583-587.

39. Saghai Maroof, M. A., Yue, Y. G., Xiang, Z. X., Stromberg, E. L., and Rufener, G. K. 1996. Identification of quantitative trait loci controlling resistance to gray leaf spot disease in maize. Theor. Appl. Genet. 93:539-546.
40. Shapiro, S. S., and Wilk, M. B. 1965. An analysis of variance test for normality (complete samples). Biometrika 52:591-611.

41. Steele, R. G. D., and Torrie, J. H. 1980. Principles and Procedures of Statistics. 2nd ed. McGraw-Hill Inc., New York.

42. Tehon, L. R., and Daniels, E. 1925. Notes on the parasitic fungi of Illinois. Mycologia 17:248.

43. Thompson, D. L., Berquist, R. R., Payne, G. A., Bowman, D. T., and Goodman, M. M. 1987. Inheritance of resistance to gray leaf spot in maize. Crop Sci. 27:243-246.

44. Thorson, P. R., and Martinson, C. A. 1993. Development and survival of Cercospora zeae-maydis germlings in different relative humidity environments. Phytopathology 83:153-157.

45. Toman, Jr., J., and White, D. G. 1993. Inheritance of resistance to anthracnose stalk rot of corn. Phytopathology 83:981-986.

46. Ulrich, J. F., Hawk, J. A., and Carroll, R. B. 1990. Diallel analysis of maize inbreds for resistance to gray leaf spot. Crop Sci. 30:1198-1200.

47. Warner, J. N. 1952. A method for estimating heritability. Agron. J. 44:427-430. 